\title{
The Study on the Guidelines of Urban Public Open Space for Non-independent Land :Taking New York and Hong Kong as Examples
}

\author{
Ying Shi ${ }^{1, a}$, Yongwen Yang ${ }^{2, b}$ \\ ${ }^{1}$ School of Architecture, South China University of Technology, Guangzhou, Guangdong, China \\ ${ }^{2}$ School of Architecture, South China University of Technology, Guangzhou, Guangdong, China \\ A13802979189@126.com, bemailyangyongwen2015@126.com
}

Keywords: Public Open Space in Private Development(POSPD); Hong Kong; New York; nature of public space; non-independent land.

Abstract. In this article, we examine the definition of the Urban Public Open Space for Non-independent Land, and understand the related legal status in China. It attempts to summarize and compare with the mechanism of the Public Open Space in Private Development (POSPD) in Hong Kong and New York, so as to draw some inspiration for the development of domestic in China. It suggests a more effective design control and better management of the public open space for the urban planning regulation system.

\section{Background}

With the rapid development of urbanization and the improvement of people's livelihood, people's need for quality of urban space is growing. However, urban construction and expansion have made the urban area dwindle; while as the vacant city space, especially urban public space faces the problem of shortage. Under the traditional state, urban public space supplied by the government has failed to meet the requirements. Therefore, some governments will attract and encourage private conducts in city construction and public administration in order to promote the city development, making the private enterprises important roles in providing public services. Therefore, the developers attempt of offering open space for rest, which is also maintained and managed by themselves, in the parcels of their private real right voluntarily or according to law for the public use, is included, and this contributes to improving the urban environment and solving the urban public space shortage. This kind of new public space is called POSPD (Public Open Space in Private Development) in Hong Kong and POPS (Privately Owned Public Space) in the US. According to the implement of the socialist public ownership of the land in China, the planning bureau in the city of Shenzhen gave it a new definition: Public Space for Non-independent Land(PSNL).

At present, China has carried out such practical revolution in urban public space which is built on land with non-public property right. Firstly, in the recent twenty years, the plot ratio has been widely introduced as a reward in the city planning administration in China. The government encourages the private development projects to provide open space, elevated ground floor, increase of public facilities, application of energy-saving construction and so on, and thus gives them additional area accordingly as awards. Secondly, some cities have given some standards and guidelines on urban planning and design, but they were not written into the laws and regulations of urban planning, resulting in a dead zone in the development and management of the planning. In 2006,the planning bureau in the city of Shenzhen compiled the document of The Public Space System Planning in Shenzhen Special Economic Zone, which became the first inland city to establish public space construction standards and guidelines and improve the planning management on the urban planning platform. At the same time, in order to cover the shortage of the planning and organization management system, which centers on controlled detailed planning, Beijing organized the formulation of Beijing CBD Core Area Urban Design Guidelines in 2010, and proposed the management and control objects and the management and control measures relating to the external public spaces of public buildings. Although Shenzhen and Beijing provided help for the practice of PSNL, it failed to form a set of systematic design management guidelines which have a legally binding effect. Thirdly, depending on the efforts of architectural designers, there are some successful 
cases under a lot of resistance, which enables providing practices of PSNL to carry out. But, it failed finally as a result of breaking away from architects' control and lacking management in the late stage. Faced with the dilemma at current stage, this article aims to explain the importance of making laws and regulations and to summarize the relevant methods through the studies of models at home and abroad such as the plans and controlling methods of POPS in New York and the POSPD in Hong Kong, so as to provide references for the legislation of laws and regulations for design and management of city space in China.

\section{Policy and public space in Hong Kong and New York}

The POSPD was first emerging in the western city, owning to the attention to problem of absence of urban public space. Since the land resources for urban development and construction and funds are hold in private hands, and the New York city government could not afford the fee purchasing land for urban public space construction, the zoning resolution established in 1961 provide the policy that improve the volume rate as a reward. This policy stimulate the single building to construct back off the building line, and transfer the space between the building and building line into the city public space. From 1961 to 1973, with the promotion of incentives and the lack of censorship, the POSPD became in volume. Afterwards, the policy of the POSPD was come in a further revision focus on the problem. Based on the database opened in 2000 collecting and study the posed POSPD, the government published some regulations for design guidelines and facilities standard in 2007, and passed the amendment of the text, emphasizing on convenience and openness of the POSPD. Following the establishment of the policy of New York, the government in Hong Kong paid attention on the construction and use of the POSPD while creating and implement the new town development planning related to public space issue in 1980s. The large public buildings construction was require to provide space in private land for city public space. The posed POSPD was list in 2008, and then the Public Open Space in Private Developments Design and Management Guidelines was system established, which has come into effect on 2011. At this stage, Hong Kong and New York have found decent policies and mechanism, consists of the following parts.

\subsection{Incentive mechanism}

Developers can obtain the volume rate awards with the provision of the POSPD, including the atrium for a public purpose, streets broaden and the passage through building .It means that while the space meet the requirements of the open space for public use, the developers can obtain more construction area as reward. Hong Kong and New York also use the "incentive mechanism of open space", and adjust the range of reward according to the different regional. In Hong Kong, the legal limit for exemption area is the total floor area of $20 \%$ or equivalent of five times of the related land (whichever is less).

\subsection{Approval Process}

In order to guarantee the quality of the POSPD, developers must be submitted to the City Planning Bureau of the POSPD design. Upon review of compliance with the design standards, grant a license, the developers could start the project applying to the Construction Bureau. The New York standard has also developed the "margin" system: developers must prepay a fee to the government, to ensure that the plaza provide the necessary facilities and appropriate management after construction. Hong Kong refine the audit procedures, when the developers take the initiative to the board TPB planning application submitted to public open space in its development, must take the MLP (Master Layout Plan) to the town planning board planning applications. The board would add the conditions above into regulations after examining the related blueprint. If possible, such provisions would become the conditions of the land lease. 


\subsection{The POSPD Information Already Gathered and Published}

In 2000,. New York City Planning Department and Harvard professor Jerold S. Kayden jointly developed an electronic database: This database not only published the basic POPS information (size, location, opening hours), but also exhibited the implementation (the number of green programs, lighting facilities, the number of dustbins, the number of tables and chairs for people to relax, etc.). The collecting and publishing of POSPD existing information makes it convenient to do specific research about the implementation of POSPD so as to provide practical examples for setting design and management standards .

On the other hand, the government agencies should provide POSPD licensed activities and management, the application files, plans and photographs of the site, in order to encourage people to use these space conveniently.

\subsection{Design the Guidance and Facilities Standards}

Design the Guidance and the Standards of Facilities New York and Hong Kong issued documents that defined the POSPD space and several related management standards in 2007 and 2011 respectively, which established a concise and flexible framework for planning, designing and managing POSPD. The ideal design of POSPD need to start from the discipline which should be attractive, open, environmental, safe and comfortable, then guide the implementation with specific design standards including space, sensory and green facilities.

First, set six criteria based on the spatial consideration: 1) Scale: The size of the space should make people pleasant; 2) Shape: The shape of the square should be regular so as to prevent partial visual obstruction; 3) Ratio of width and depth: The aspect ratio should be appropriate so as to make people convenient to use; 4) Major and Minor portions: The major proportion is the main space while the minor space is easy to see and connected with the main space; 5) Location: Can be placed in the public site which is adjacent to the private project site; 6) Orientation: Make sure the site has a south-facing sun.

Second, set seven criteria based on the sensory factors: 1) Visibility: Ensure that the degree of opening; 2) Through Block Plazas: Handle the relation among the square, the sidewalk and the buildings adjacent to them well so as to improve its attractiveness ; 3 ) Sidewalk Frontages: Make the space between two blocks creatively; 4) Elevation difference: Moderate elevation differences can make the space interesting; 5) Steps: Ensure that the size is compliant to security criteria; 6) Residence time and Circulation route: Increase the residence time and design the cycle path; 7) Permitted Obstructions: Prohibition obstructions such as garage entrances, parking, mechanical equipment, such obstructions.

Third, set a series of mandatory requirements on green facilities including: the number and the forms of seats, green planting (species, location, post-irrigation, etc.), lighting and trash containers, ground covering, signs (indicating the number of facilities within the site, the owner and

\begin{tabular}{l}
\hline \\
Space considerations \\
Scale \\
Shape \\
Ratio of width and depth \\
Major and Minor portions \\
Location \\
Orientation \\
Sensory factors \\
Visibility \\
Through Block Plazas \\
Sidewalk Frontages \\
Elevation \\
Steps \\
Residence time and Circulation route \\
Permitted Obstructions \\
Green and Facilities \\
Seating \\
Planting and Trees \\
Lighting \\
Ground Coverings \\
Litter Receptacles \\
Bicycle Parking \\
Signage \\
Facilities for disabled \\
regionally characteristic \\
Additional required amenities
\end{tabular}

(Fig.1 Summarize Design Standard in Hong Kong and New York)

parking, disabled facilities, etc. Developers are also encouraged to provide a venue business functions 
and increase its geographical characteristics set fountains, pools, sculpture, book kiosks, outdoor cafes and other additional facilities.

By statisticsing and contrasting the specific measures in Hong Kong and New York design criteria (Fig. 1), Chinese government can make better decision in POSPD related issues. The criteria of New York is more completed than the one in Hong Kong, and the design guidance in Hong Kong should introduce a wider range of contents to the integrate both local and site environmental changes to achieve good spatial effects.

\subsection{Operation and Management Standard}

After the construction of the POSPD, generally the development project was managed and maintained by private owners, which including the following aspects:First, Openness: allow public access to enjoy the facilities for legitimate purposes, to ensure the public channel unblocked, should not set up obstacles (gate, fence)to refuse to public use. Second, Opening Time: generally speaking, prescribed time period of development in accordance, there are minimum requirements. Those act as function of pedestrian channel should be 24 hours open. Part of the ground under the premise of ensuring public safety and protection facilities, can apply for a night off. Third, Transparency and Information Disclosure: the Internet to provide documents and information available to the public and participate in supervision. At the same time, a prominent announcement should be set in POSPD. Fourth, Security and Monitoring: prevent illegal users. Fifth, Maintenance: including gardening, facilities maintenance and so on. Sixth, Licensing activities: allow non-commercial exhibitions, programs or charitable activities and performances, that shall obtain the approval of relevant departments. Encourage commercial activities (food service facilities, catering services, such as open Coffee kiosks) in conjunction with the POSPD use, but with strictly size control.

\section{The evaluation and supplement of Hongkong and New York.}

The development of POPS and POSPD is relatively stable from the construction of 1960's, 1980's to today. And it have good results in the application of the both city, but there are still developing with the existing dissatisfied examples. Design guidelines for systematic control range must cover all aspects of land, to further enhance the quality of public space to make the user feel comfortable and satisfied, which needs further supplement on top of.

\subsection{The Nature of Public Space and Openness}

Some owners abused administrative power restricting the appearance of the public activities in the POSPD. In order to prevent the crime, POSPD can be closed at night for security management. Many of the POSPD set of gates and fences. But it does not provide the appropriate size of the obstacle, or removed during the day. The POSPD has become a symbol of the "fortress" at daytime, for just opening the door for a limited time, which reduce its openness and accessibility.Therefore, guidance for the door, wall, floor height and any other elements are necessary, preventing the emergence of the symbolic field. Moreover, the nature of public space was treat by another security management. The highly monitoring and strictly security reduce the personal privacy and openness. The number of camera monitoring and placement should be detailed provisions. Meanwhile, the interests of the public need to be take into account by the security management method.

The development of POSPD can't separated from the prosperity of commercial activities, but the excessive commercialization was against to non customer interests. The open Coffee shop provide furniture only available for consumers, virtually limiting the use of the crowd. It means that the ones who can afford to the goods may enjoy the privileges and the priority of public space. The POSPD owners need to sign some terms with the merchants, banning the illegal occupy, and no blocking the entrance and pedestrian walkways which affect the primary function of POSPD. 


\subsection{Guidelines for Details}

Although the detailed guidelines established in New York and Hong Kong, have done a quantitative description of the most of standard size and facilities number, effectively controlling the quality of space. But there are many cases that only meet the minimum requirements, resulting in poor spatial effect that did not achieve the desired goal. The guidelines should provide more detailed parameters depending on different site conditions.

\subsection{The Effectiveness of Government Regulation}

So far, the New York city and Hong Kong have not set up a perfect systematic, periodic POPS monitoring system, and mainly depend on other departments (such as planning bureau), social organizations and individual citizens' "complaints" to know the situation. When receiving the complaint, it sent the "supervisor" to the site to verify the situation, which means that the Construction Bureau does not actually grasp the first-hand information in the first time, delaying the whole process of supervision and thus leaving a large number of management loopholes. The process of identification and decision-making of the relevant departments were not transparent. Even if there is a means of administrative penalties issued notice or penalty, but the penalty amount so low that it can't effectively curb the illegal behavior. The most worthy of reflection is how to make the public participate in the decision-making process of POSPD construction and management. To create a real public space, only in public interest can we bring the effective planning control and management supervision system.

\section{Conclusion}

In the future development of PSNL, it would be a part of elements into the city space like the overhead space, corridors, the roof space or courtyard. And the PSNL creates a systemic city public space image, which makes the urban public space more continuous at the same time. So we must vigorously promote and implement PSNL guidelines, so that the owners realize that it is a long-term interests of the win-win situation.

Summarizing the New York and Hong Kong's policy, this paper gains some experience from them, reveals the importance of the policy system of incentive mechanism, the approval procedures, information disclosure, design and management guidelines. However, in China, due to the differences of the policy background and the change of land form, some problems may be occurred need to be solve. In order to make full use of the PSNL policy in China, the government must adjust the current policy, suitable for the local culture and urban conditions.

\section{References}

[1] Huang, H.B. 2014. Public Space of Private Property: Experience in New York and Hong Kong: Its Revelation and Reference to Dongguan Land Plot Packing. Chinese \& Overseas Architecture2014(03): 81-83.

[2] Nameless, 2006 A study on the total floor area of the building approved for exemption. Hong Kong: Development Bureau.

[3] Schmidt, S., Nemeth, J. \& Botsford, E. 2011. The evolution of privately owned public spaces in New York City. Urban Design International.16(4): 270-284.

[4] LUK.W.L. 2009. Privately owned public space in Hong Kong and New York: The urban and spatial influence of the policy. International Forum on Urbanism2009(4): 694-704.

[5] Kayden, J. S., NYCDCP \& NYMAS. 2000. Privately owned public space. New York: John Wiley \& Sons Inc. 